\title{
The venous delay phenomenon in computed tomography angiography: a novel imaging outcome predictor for poor cerebral perfusion after severe aneurysmal subarachnoid hemorrhage
}

\author{
*Po-Chuan Hsieh, MD, ${ }^{1}$ Yi-Ming Wu, MD, ${ }^{2}$ Alvin Yi-Chou Wang, MD, ${ }^{1}$ Ching-Chang Chen, MD,1 \\ Chien-Hung Chang, MD, ${ }^{3}$ Shy-Chyi Chin, MD, ${ }^{2}$ Tai-Wei Erich Wu, MPH, ${ }^{1}$ Chieh-Tsai Wu, MD, ${ }^{1}$ and \\ Shih-Tseng Lee, MD'
}

Departments of ${ }^{1}$ Neurosurgery, ${ }^{2}$ Medical Imaging and Intervention, and ${ }^{3}$ Neurology, Chang Gung Memorial Hospital, Linkou,
Chang Gung University and Medical College, Kweishan, Taoyuan, Taiwan

OBJECTIVE Diverse treatment results are observed in patients with poor-grade aneurysmal subarachnoid hemorrhage (aSAH). Significant initial perfusion compromise is thought to predict a worse treatment outcome, but this has scant support in the literature. In this cohort study, the authors correlate the treatment outcomes with a novel poor-outcome imaging predictor representing impaired cerebral perfusion on initial CT angiography (CTA).

METHODS The authors reviewed the treatment results of 148 patients with poor-grade aSAH treated at a single tertiary referral center between 2007 and 2016. Patients with the "venous delay" phenomenon on initial CTA were identified. The outcome assessments used the modified Rankin Scale (mRS) at the 3rd month after aSAH. Factors that may have had an impact on outcome were retrospectively analyzed.

RESULTS Compared with previously identified outcome predictors, the venous delay phenomenon on initial CTA was found to have the strongest correlation with posttreatment outcomes on both univariable $(p<0.0001)$ and multivariable analysis (OR 4.480, 95\% Cl 1.565-12.826; $p=0.0052$ ). Older age and a higher Hunt and Hess grade at presentation were other factors that were associated with poor outcome, defined as an mRS score of 3 to 6 .

CONCLUSIONS The venous delay phenomenon on initial CTA can serve as an imaging predictor for worse functional outcome and may aid in decision making when treating patients with poor-grade aSAH.

https://thejns.org/doi/abs/10.3171/2017.5.JNS17794

KEY WORDS subarachnoid hemorrhage; cerebrovascular circulation; computed tomography angiography; vascular disorders

\begin{abstract}
A NEURYSMAL subarachnoid hemorrhage (aSAH) exhibits diverse outcomes, with some patients suffering from a devastating course after initial bleeding and others recovering completely from the acute event. Despite the availability of several clinical outcome assessments, early prediction of the course in patients with severe aSAH remains inaccurate. This is a critical issue for decision making and prognosis evaluation. ${ }^{20}$ Currently, the best outcome predictors in patients with aSAH are thought to be those highly correlated with the initial clinical presentation, such as the Hunt and Hess scale and the World Federation of Neurosurgical Societies grade. ${ }^{19}$ The Fisher grade is another commonly used imaging grading system
\end{abstract}

that predicts the possibility of delayed neurological deficits according to the results of initial CT. ${ }^{3}$ Although up to 40 different clinical assessment tools have been proposed for this purpose, there is no universal consensus on which is most useful. ${ }^{10,15}$

After aSAH, the increased intracranial pressure (ICP) and possible ultra-early vasospasm resulting from arterial bleeding is thought to result in compromised global perfusion and poor clinical outcomes. ${ }^{1,5}$ Several authors have proposed the use of a perfusion study, such as CT perfusion (CTP) or MR perfusion, to evaluate the deficit after aSAH and its correlation with clinical outcomes ${ }^{6,11,23}$ However, the use of perfusion studies in the emergency department (ED)

ABBREVIATIONS aSAH = aneurysmal subarachnoid hemorrhage; CTA = CT angiography; $C T P=$ CT perfusion; ED = emergency department; ICP = intracranial pressure; $\mathrm{MIP}=$ maximal intensity projection; MLS = midline shift; $\mathrm{mRS}=$ modified Rankin Scale; ROI = region of interest.

SUBMITTED March 29, 2017. ACCEPTED May 23, 2017.

INCLUDE WHEN CITING Published online November 24, 2017; DOI: 10.3171/2017.5.JNS17794.

* Drs. Hsieh and Y. M. Wu contributed equally to this work and share first authorship. 
setting is relatively time-consuming and has other limitations, including the need for large-bore venous access and additional contrast media, complicated image processing and interpretation, and a low success rate for critically ill, agitated patients. In comparison, CT angiography (CTA) has been more widely used over the past several decades as the first-line survey for spontaneous $\mathrm{SAH}-$ with satisfactory sensitivity, specificity, and cost-effectiveness in the ED setting. ${ }^{22}$ The arterial and cortical attenuation on CTA source images potentially represents the macro- and microcirculation, respectively. ${ }^{14}$ Based on the idea of intracranial circulation compromise after severe aSAH, we propose that the "venous delay" phenomenon on CTA may serve as a feasible, novel imaging indicator for global hypoperfusion and the resulting poor outcomes. We attempt to correlate this finding with the midterm outcomes after aneurysm treatment in our patient series.

\section{Methods}

We retrospectively reviewed the records of patients who suffered from severe aSAH with an initial Hunt and Hess grade of IV or V at a single tertiary referral center. The study protocol was reviewed and approved by the institutional review board of the Chang Gung Memorial Hospital. All patients were seen between December 2007 and December 2016. The bleeding source of a ruptured aneurysm was confirmed by CTA in all patients and was treated by either surgical clipping or endovascular coiling. The exclusion criteria were a patient age of less than 18 years, a lack of CTA imaging or imaging of inadequate quality, rebleeding episode before definitive treatment, documented procedure-related events (e.g., iatrogenic parent artery compromise) with a significant impact on outcome, or the presence of other suspected causes of secondary intracranial hemorrhage (e.g., vascular malformation, traumatic hemorrhage, neoplasm, or possible hemorrhagic transformation after ischemic stroke).

Plain CT images were used as the primary diagnostic tool in the ED. After confirming the diagnosis of spontaneous SAH, CTA was performed to assess the possible etiology. If necessary, a single bolus of a sedative agent such as midazolam $(0.1-0.3 \mathrm{mg} / \mathrm{kg})$ or propofol $(0.5-1 \mathrm{mg} / \mathrm{kg})$ was given before the examination. A 64-row detector scanner (Aquilion 64; Toshiba America Medical Systems) was used to obtain CTA from the level of the carina to the vertex. The scanning parameters were $120 \mathrm{kVp}$, tube current adjusted by an automatic exposure control system with a maximal value of $500 \mathrm{~mA}$ at shoulder level; a field of view of $24 \mathrm{~cm}$; a slice thickness of $0.5 \mathrm{~mm}$; a gantry rotation time of 0.5 seconds; a helical pitch of 0.828 ; a table speed of $5.3 \mathrm{~cm} / \mathrm{second}$; and a scanning time of approximately 5 seconds. The injection volume and rate of iodine contrast medium (iohexol [Omnipaque 350]; GE Healthcare) was $90-100 \mathrm{ml}$ at 2.5 to $3 \mathrm{ml} / \mathrm{second}$, depending on the size and location of the venous needle. A rounded region of interest (ROI) was placed at the descending thoracic aorta to measure the density-time curve, and scanning was started when the density of the ROI exceeded 150 Hounsfield units. The acquired volume data were reconstructed into continuous 3-mm axial images. To enhance the visibility of the vessels, the image processing consisted of maximal intensity projection (MIP) on axial, coronal, and sagittal planes, with a thickness of $20 \mathrm{~mm}$ and an interval of 5 $\mathrm{mm}$. 3D volume renderings of spiral CT data were also used to facilitate diagnostic reliability.

All patients were admitted to the neurointensive care unit after the aSAH event. Aneurysm treatment included coiling and clipping, based on the patient's age, risk factors for general anesthesia, the family's preference, and the consensus of the neurosurgeon and the interventional neuroradiologist. External ventricular drainage was used routinely for all patients with poor-grade aSAH for possible associated increased ICP, hydrocephalus, and ICP monitoring in the acute postoperative period. Permanent shunting procedures were performed based on the neurosurgeon's clinical judgment, usually 1-2 weeks after the initial event. An intravenous or oral calcium channel blocker (nimodipine [Nimotop]) was given to all patients for prevention of delayed cerebral ischemia, unless its use was contraindicated by the presence of an allergy or profound shock despite aggressive resuscitation. Euvolemia was targeted during the initial postoperative course in the neurointensive care unit. Hyperdynamic fluid therapy, such as hypertension, hemodilution, and hypervolemia, was reserved for patients with imaging or clinical evidence of new cerebral ischemia or infarct.

Clinical data were collected and extracted from the medical records. The outcome assessments at 3 months postoperatively used the modified Rankin Scale (mRS) and were collected by chart review. Two neuroradiologists were responsible for reviewing the CTA images independently. The venous delay phenomenon was defined as significantly diminished or absent contrast filling of the internal cerebral veins and major sinuses (including the straight, transverse, and sigmoid sinuses) on axial MIP images (Fig. 1). We documented the physiological parameters that may have been responsible for poor systemic and brain perfusion, including systolic blood pressure, preexisting heart disease, hypertension, and the use of inotropic agents in the ED. Other common outcome variables were also evaluated, including the initial Fisher grade, the location of the aneurysm (anterior or posterior circulation), focal intracerebral hematoma, and a midline shift (MLS) on initial CT imaging. ${ }^{3}$

In the univariate analysis, the associations between the venous delay phenomenon and other clinical factors as well as those between each clinical factor and the patient outcome were tested by the chi-square test, Fisher exact test, and Student t-test. We also used multivariate logistic regression models to evaluate whether the venous delay phenomenon was an independent prognostic factor after adjusting other risk factors. The significance level was 0.05 , and all $\mathrm{p}$ values were shown in 2-tailed tests. Statistical analyses were performed using SAS software, version 9 (SAS Institute, Inc.).

\section{Results}

A total of 148 patients with $130(87.8 \%)$ coiling and 18 $(12.2 \%)$ clipping procedures were included. The mean age was 59.1 years, ranging from 19 to 90 years. There was a female predominance, with 56 male (37.8\%) and 92 female (62.2\%) patients represented. Sixty patients $(40.5 \%)$ had a history of hypertension before the SAH event; however, 

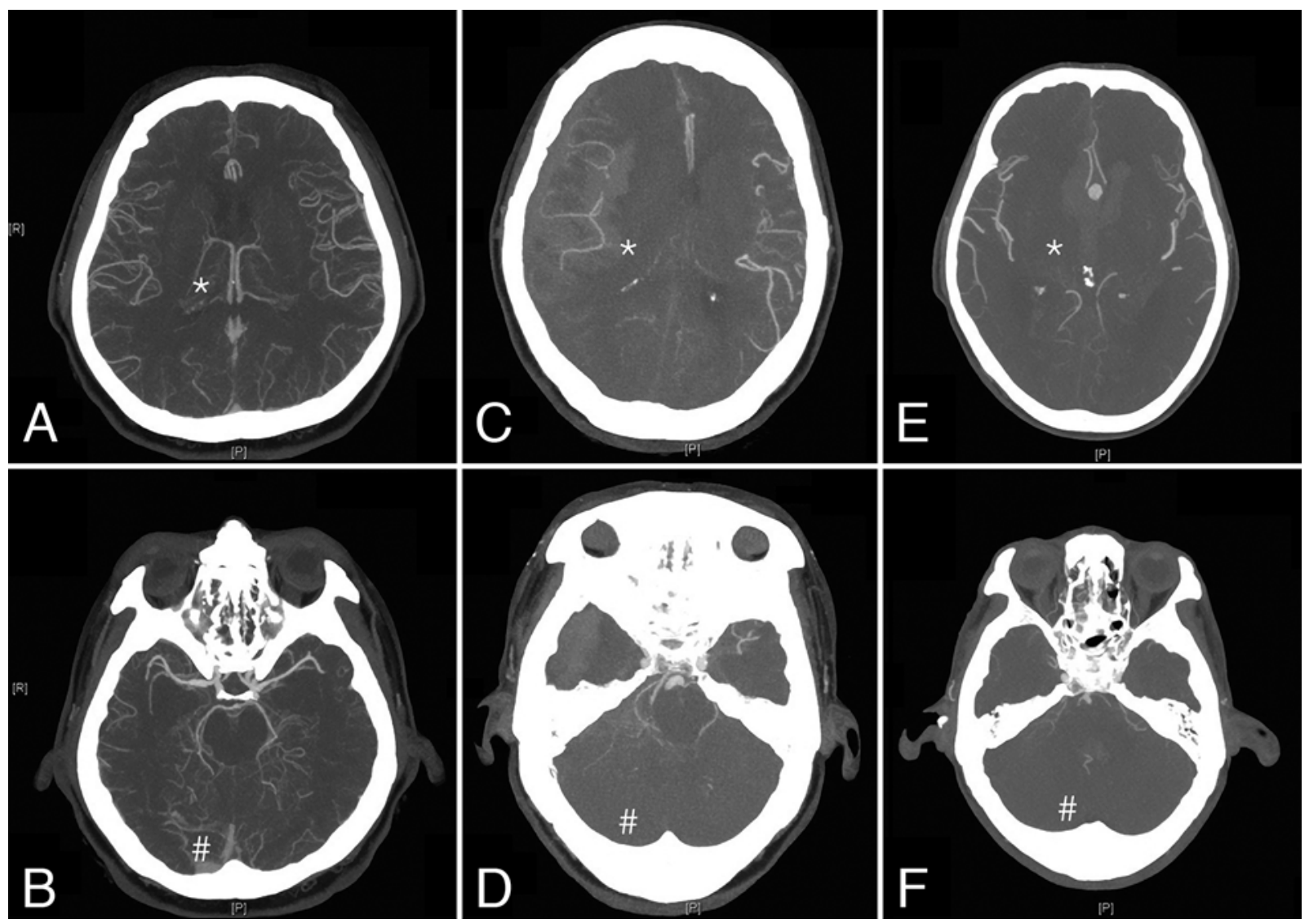

FIG. 1. Venous delay phenomenon demonstrated on CTA with MIP_images were obtained in 3 patients. A and B: Case 1 (no venous delay). Contrast pooling in the internal cerebral veins (asterisk) in a patient with low-grade aSAH with no venous delay phenomenon (A). Contrast pooling in the sinuses (pound sign) of the same patient (B). C and D: Case 2 (partial venous delay). Low-attenuation contrast signal in the internal cerebral veins in a patient with partial venous delay $(C)$; no contrast signal in the sinuses (D). E and F: Case 3 (complete venous delay). Total venous delay phenomenon in a patient with a ruptured anterior communicating artery aneurysm and a Hunt and Hess grade of $\mathrm{V}$. The patient died 4 days after initial surgical clipping and ventricular drainage because of multiple infarcts identified on immediate postoperative CT. Note that in Cases 2 and 3 the asterisks denote the assumed location of the internal cerebral veins and the pound signs that of the sinuses; these structures were either poorly visualized or not visualized on CTA in these patients.

preexisting cardiac disease (heart failure or valvular heart disease) was relatively rare in our series (6/148 [4\%]). Four patients $(2.7 \%)$ presented with shock and were treated with inotropic agents after resuscitation in the ED. Three patients $(2.0 \%)$ underwent CTA while in persistent shock (systolic blood pressure $<90 \mathrm{~mm} \mathrm{Hg}$ ) despite treatment. A total of 104 patients (70.3\%) had Hunt and Hess Grade IV aSAH; the other 44 had a grade of V (29.7\%). The majority of patients bled from an anterior circulation aneurysm (112/148 [75.7\%]). More than one-quarter (39/148 [26.3\%]) presented with a focal mass such as an intracerebral hematoma. However, only 12 patients had significant midline structure deviation resulting from these intracranial masses (12/148 [8.1\%]). The distribution of midterm outcomes by $\mathrm{mRS}$ at the 3rd postoperative month is presented in Table 1. Overall, $54.1 \%$ of patients obtained a good outcome, defined as an mRS score of $0-2$. The venous delay phenomenon was found in 29 patients (19.6\%). The association between the venous delay phenomenon and other clinical characteristics is shown in Table 2.

Preexisting heart disease (heart failure or valvular heart disease), the use of inotropic agents in the ED, and undergoing CTA while in a state of shock were considered to have an impact on systemic circulation and, secondarily, brain perfusion. However, these physiological variables showed no significant association with the venous delay phenomenon; none of the 3 patients undergoing CTA while in shock had a positive finding. Neither preexisting hypertension nor the location of the aneurysm showed a significant association with the venous delay phenomenon.

The commonly used grading systems, including Hunt and Hess and the Fisher grade, were strongly associated with the presence of the venous delay phenomenon. $\mathrm{Pa}$ tients with a higher Hunt and Hess grade (Grade V, 15/44 [34.1\%]; $p=0.0039$ ) or a higher Fisher grade (Grade 4, $23 / 84$ [27.4\%]; $p=0.0133$ ) were found to have more frequent delayed venous phases on CTA. The presence of a focal mass, a criterion of a higher Fisher grade, was also associated with our imaging predictor $(p=0.0118)$. However, not all focal masses resulted in a MLS on CT. The global mass effect had a tendency $(p=0.0591)$ to be related to the venous delay phenomenon, although this was not 
TABLE 1. Baseline characteristics in 148 patients with poor-grade aSAH

\begin{tabular}{|c|c|}
\hline Characteristics & Value \\
\hline \multicolumn{2}{|l|}{ Sex } \\
\hline Female & $92(62.2)$ \\
\hline Male & $56(37.8)$ \\
\hline Age, yrs, mean \pm SD & $59.1 \pm 13.6$ \\
\hline \multicolumn{2}{|l|}{ Heart disease } \\
\hline No & $142(96.0)$ \\
\hline Yes & $6(4.0)$ \\
\hline \multicolumn{2}{|l|}{ Hypertension } \\
\hline No & $88(59.5)$ \\
\hline Yes & $60(40.5)$ \\
\hline \multicolumn{2}{|l|}{ Inotropic agent } \\
\hline No & $144(97.3)$ \\
\hline Yes & $4(2.7)$ \\
\hline Systolic blood pressure, mean \pm SD & $145.4 \pm 29.5$ \\
\hline$\geq 90 \mathrm{~mm} \mathrm{Hg}$ & $145(98.0)$ \\
\hline$<90 \mathrm{~mm} \mathrm{Hg}$ & $3(2.0)$ \\
\hline \multicolumn{2}{|l|}{ Venous delay on CT } \\
\hline No & $119(80.4)$ \\
\hline Yes & $29(19.6)$ \\
\hline \multicolumn{2}{|l|}{ Hunt \& Hess grade } \\
\hline IV & $104(70.3)$ \\
\hline V & $44(29.7)$ \\
\hline \multicolumn{2}{|l|}{ Fisher grade on CT } \\
\hline 2 & $5(3.4)$ \\
\hline 3 & $59(39.9)$ \\
\hline 4 & $84(56.8)$ \\
\hline \multicolumn{2}{|l|}{ Location } \\
\hline Posterior circulation & $36(24.3)$ \\
\hline Anterior circulation & $112(75.7)$ \\
\hline \multicolumn{2}{|l|}{ Focal mass } \\
\hline No & $109(73.7)$ \\
\hline Yes & $39(26.3)$ \\
\hline \multicolumn{2}{|l|}{$M L S>5 \mathrm{~mm}$} \\
\hline No & $136(91.9)$ \\
\hline Yes & $12(8.1)$ \\
\hline \multicolumn{2}{|l|}{ Outcome at 3rd mo, mRS score } \\
\hline 0 & $34(23.0)$ \\
\hline 1 & $32(21.6)$ \\
\hline 2 & $14(9.5)$ \\
\hline 3 & $14(9.5)$ \\
\hline 4 & $27(18.2)$ \\
\hline 5 & $11(7.4)$ \\
\hline 6 & $16(10.8)$ \\
\hline \multicolumn{2}{|l|}{ Procedure } \\
\hline Embolization & $130(87.8)$ \\
\hline Surgery & $18(12.2)$ \\
\hline
\end{tabular}

Data presented as number (\%) unless specified otherwise.

TABLE 2. Association of clinical characteristics with venous delay phenomenon on CTA with MIP

\begin{tabular}{|c|c|c|c|}
\hline \multirow[b]{2}{*}{ Characteristics } & \multicolumn{2}{|c|}{ Venous Delay } & \multirow{2}{*}{$\begin{array}{c}\mathrm{p} \\
\text { Value }\end{array}$} \\
\hline & No & Yes & \\
\hline Sex & & & 0.1962 \\
\hline Female & $77(83.7)$ & $15(16.3)$ & \\
\hline Male & $42(75.0)$ & $14(25.0)$ & \\
\hline Age, yrs, mean $\pm S D$ & $58.8 \pm 13.7$ & $60.5 \pm 13.1$ & $0.5473 \dagger$ \\
\hline Heart disease & & & $0.3345^{*}$ \\
\hline No & $115(81.0)$ & $27(19.0)$ & \\
\hline Yes & $4(66.7)$ & $2(33.3)$ & \\
\hline Hypertension & & & 0.9183 \\
\hline No & $71(80.7)$ & $17(19.3)$ & \\
\hline Yes & $48(80.0)$ & $12(20.0)$ & \\
\hline Inotropic agent & & & $0.1724^{*}$ \\
\hline No & 117 (81.3) & $27(18.7)$ & \\
\hline Yes & $2(50.0)$ & $2(50.0)$ & \\
\hline $\begin{array}{l}\text { Systolic blood pressure, } \\
\text { mean } \pm \text { SD }\end{array}$ & $144.0 \pm 29.2$ & $151.0 \pm 30.4$ & $0.2567 \dagger$ \\
\hline$\geq 90 \mathrm{~mm} \mathrm{Hg}$ & $117(80.7)$ & $28(19.3)$ & $0.4828^{*}$ \\
\hline$<90 \mathrm{~mm} \mathrm{Hg}$ & $2(66.7)$ & $1(33.3)$ & \\
\hline Hunt \& Hess grade & & & 0.0039 \\
\hline IV & $90(86.5)$ & $14(13.5)$ & \\
\hline V & $29(65.9)$ & $15(34.1)$ & \\
\hline Fisher grade on CT & & & $0.0133^{*}$ \\
\hline 2 & $4(80.0)$ & $1(20.0)$ & \\
\hline 3 & $54(91.5)$ & $5(8.5)$ & \\
\hline 4 & $61(72.6)$ & $23(27.4)$ & \\
\hline Location & & & 0.3476 \\
\hline Posterior circulation & $27(75.0)$ & $9(25.0)$ & \\
\hline Anterior circulation & $92(82.1)$ & $20(17.9)$ & \\
\hline Focal mass & & & 0.0118 \\
\hline No & $93(85.3)$ & $16(14.7)$ & \\
\hline Yes & $26(66.7)$ & $13(33.3)$ & \\
\hline $\mathrm{MLS}>5 \mathrm{~mm}$ & & & $0.0591^{*}$ \\
\hline No & $112(82.4)$ & $24(17.6)$ & \\
\hline Yes & $7(58.3)$ & $5(41.7)$ & \\
\hline $\begin{array}{l}\text { Outcome at 3rd mo after } \\
\text { event, mRS score }\end{array}$ & & & $0.0023^{*}$ \\
\hline 0 & $32(94.1)$ & $2(5.9)$ & \\
\hline 1 & $28(87.5)$ & $4(12.5)$ & \\
\hline 2 & $14(100.0)$ & $0(0.0)$ & \\
\hline 3 & $8(57.1)$ & $6(42.9)$ & \\
\hline 4 & $19(70.4)$ & $8(29.6)$ & \\
\hline 5 & $8(72.7)$ & $3(27.3)$ & \\
\hline 6 & $10(62.5)$ & $6(37.5)$ & \\
\hline $\begin{array}{l}\text { Outcome at 3rd mo after } \\
\text { event, mRS score group }\end{array}$ & & & $<0.0001$ \\
\hline $0-2$ & $74(92.5)$ & $6(7.5)$ & \\
\hline $3-6$ & $45(66.2)$ & $23(33.8)$ & \\
\hline
\end{tabular}


» CONTINUED FROM PAGE 879

TABLE 2. Association of clinical characteristics with venous delay phenomenon on CTA with MIP

\begin{tabular}{|c|c|c|c|}
\hline \multirow[b]{2}{*}{ Characteristics } & \multicolumn{2}{|c|}{ Venous Delay } & \multirow{2}{*}{$\begin{array}{c}p \\
\text { Value }\end{array}$} \\
\hline & No & Yes & \\
\hline Procedure & & & $0.3507^{*}$ \\
\hline Embolization & $106(81.5)$ & $24(18.5)$ & \\
\hline Surgery & $13(72.2)$ & $5(27.8)$ & \\
\hline
\end{tabular}

Data presented as number (\%) unless specified otherwise.

* Fisher exact test.

$\dagger$ Student t-test.

statistically significant. We defined a poor outcome as an mRS score of 3-6, documented 3 months after the initial aSAH event. Patient age $(\mathrm{p}=0.0314)$, a higher Hunt and Hess grade $(p=0.0015)$, a higher Fisher grade $(p=0.0131)$, and the presence of a focal mass effect $(p=0.0007)$ were found to have a statistically significant association with poor outcome on univariable analysis (Table 3 ). The presence of a venous delay phenomenon $(\mathrm{p}<0.0001)$ was found to have the highest association. On multivariable analysis, the venous delay phenomenon (OR 4.480, 95\% CI 1.565-12.826; $\mathrm{p}=0.0052$ ), patient age (OR 1.382, 95\% CI 1.044-1.828; $\mathrm{p}=0.0236)$, and the Hunt and Hess grade (OR 2.606, 95\% CI 1.101-6.167; $\mathrm{p}=0.0294$ ) were found to be significantly associated with a poor outcome. The Fisher grade $(p=0.5046)$ had no significant correlation, and the presence of a focal mass $(\mathrm{p}=0.0606)$ showed only a slight tendency toward an association after adjusting for potential confounders (Table 4).

\section{Discussion}

We describe a retrospective cohort study of 148 patients with poor-grade aSAH who received surgical or endovascular obliteration of a ruptured aneurysm, with diverse outcomes at midterm follow-up. Clinical decision making is difficult in this patient group, and treatment results are sometimes confusing: whereas some patients have excellent outcomes, others do not, despite aggressive neurointensive treatment. ${ }^{16}$ Many efforts have been made to address proper diagnosis and patient stratification for better understanding and prediction of treatment outcomes after poor-grade aSAH. $3,4,9,10,12,13,15,17,19-21$ However, to date there is no universally accepted grading system.

Significant changes in ICP and cerebral hemodynamics develop after aSAH. Increased ICP is common, and worse outcomes are observed in patients who do not respond to its treatment. ${ }^{5}$ The direct impact of increased ICP on cerebral hemodynamics is compromised cerebral perfusion, which has been widely documented in patients with traumatic brain injury. In patients with aSAH, delayed cerebral ischemia with vasospasm is also a well-known complication after the rupture event. However, the immediate effect of aSAH on cerebral hemodynamics during the acute phase after bleeding is less frequently discussed. ${ }^{1}$

In patients with aSAH, CTA has gradually become a widely used imaging modality over the last several decades for primary surveillance of the bleeding source..$^{2,7,22}$
TABLE 3. Three-month outcome association on univariable analysis

\begin{tabular}{|c|c|c|c|}
\hline \multirow[b]{2}{*}{ Characteristics } & \multicolumn{2}{|c|}{$\begin{array}{c}\text { Outcome at 3rd Mo } \\
\text { After Event }\end{array}$} & \multirow[b]{2}{*}{$\begin{array}{c}p \\
\text { Value }\end{array}$} \\
\hline & $\begin{array}{l}\text { Good, mRS } \\
0-2\end{array}$ & $\begin{array}{c}\text { Poor, mRS } \\
3-6\end{array}$ & \\
\hline Sex & & & 0.4400 \\
\hline Female & $52(56.5)$ & $40(43.5)$ & \\
\hline Male & $28(50.0)$ & $28(50.0)$ & \\
\hline Age, yrs, mean \pm SD & $56.9 \pm 12.9$ & $61.8 \pm 14.0$ & $0.0314 \dagger$ \\
\hline Heart disease & & & $0.9999^{*}$ \\
\hline No & $77(54.2)$ & $65(45.8)$ & \\
\hline Yes & $3(50.0)$ & $3(50.0)$ & \\
\hline Hypertension & & & 0.1365 \\
\hline No & $52(59.1)$ & $36(40.9)$ & \\
\hline Yes & $28(46.7)$ & $32(53.3)$ & \\
\hline Inotropic agent & & & $0.9999^{*}$ \\
\hline No & $78(54.2)$ & $66(45.8)$ & \\
\hline Yes & $2(50.0)$ & $2(50.0)$ & \\
\hline $\begin{array}{l}\text { Systolic blood pressure, } \\
\text { mean } \pm S D\end{array}$ & $142.8 \pm 25.8$ & $148.4 \pm 33.3$ & $0.2623 \dagger$ \\
\hline$\geq 90 \mathrm{~mm} \mathrm{Hg}$ & $80(55.2)$ & $65(44.8)$ & $0.0947^{*}$ \\
\hline$<90 \mathrm{~mm} \mathrm{Hg}$ & $0(0.0)$ & $3(100.0)$ & \\
\hline Hunt \& Hess grade & & & 0.0015 \\
\hline IV & $65(62.5)$ & $39(37.5)$ & \\
\hline V & $15(34.1)$ & $29(65.9)$ & \\
\hline Venous delay & & & $<0.0001$ \\
\hline No & $74(62.2)$ & $45(37.8)$ & \\
\hline Yes & $6(20.7)$ & $23(79.3)$ & \\
\hline Fisher grade on CT & & & $0.0131^{*}$ \\
\hline 2 & $3(60.0)$ & $2(40.0)$ & \\
\hline 3 & $40(67.8)$ & $19(32.2)$ & \\
\hline 4 & $37(44.0)$ & $47(56.0)$ & \\
\hline Fisher grade on CT-grouped & & & 0.0051 \\
\hline $2-3$ & $43(67.2)$ & $21(32.8)$ & \\
\hline 4 & $37(44.0)$ & $47(56.0)$ & \\
\hline Location & & & 0.5747 \\
\hline Posterior circulation & $18(50.0)$ & $18(50.0)$ & \\
\hline Anterior circulation & $62(55.4)$ & $50(44.6)$ & \\
\hline Focal mass & & & 0.0007 \\
\hline No & $68(62.4)$ & $41(37.6)$ & \\
\hline Yes & $12(30.8)$ & $27(69.2)$ & \\
\hline$M L S>5 \mathrm{~mm}$ & & & 0.1330 \\
\hline No & $76(55.9)$ & $60(44.1)$ & \\
\hline Yes & $4(33.3)$ & $8(66.7)$ & \\
\hline Procedure & & & 0.1683 \\
\hline Embolization & $73(56.2)$ & $57(43.8)$ & \\
\hline Surgery & $7(38.9)$ & $11(61.1)$ & \\
\hline
\end{tabular}

Data presented as number (\%) unless specified otherwise.

* Fisher exact test.

$\dagger$ Student t-test. 
TABLE 4. Multivariate logistic regression for poor outcome (mRS Score 3-6 at 3rd postoperative month)

\begin{tabular}{lll}
\hline \multicolumn{1}{c}{ Covariates } & $p$ Value & Adjusted OR $(95 \%$ Cl) \\
\hline Venous delay, yes & 0.0052 & $4.480(1.565-12.826)$ \\
\hline Age, per 10-yr increase & 0.0236 & $1.382(1.044-1.828)$ \\
\hline Hunt \& Hess grade, V & 0.0294 & $2.606(1.101-6.167)$ \\
\hline Fisher grade, 4 & 0.5046 & $1.347(0.561-3.235)$ \\
\hline Focal mass, yes & 0.0606 & $2.485(0.960-6.431)$ \\
\hline
\end{tabular}

The arterial phase is estimated, using an automated exposure control system, with the ROI over the descending aorta. The scan starts when there is enough contrast medium delivered through the ROI. However, delayed cerebral perfusion with secondary diminished venous enhancement is sometimes observed in patients with increased ICP. A scan delay, determined by a preexamination contrast test dose, may be needed in these patients to obtain a better image quality for diagnosis, according to a previous report. ${ }^{8}$ This phenomenon demonstrates the existence of perfusion delay in patients with aSAH in the acute phase; this delay theoretically results in a harmful effect.

Some studies are have focused on early perfusion deficits after aSAH. ${ }^{6,11,18,23}$ In one study of CTP, early circulatory disturbance was observed, with decreased cerebral blood flow and increased mean transit time; this was associated with poor outcomes. ${ }^{6}$ Elevated ICP and microcirculatory vasoconstriction are the proposed mechanisms related to these cerebral circulation deficits. In another study of CTP, a focal circulatory disturbance over the bilateral thalami was found to have an impact on outcome. ${ }^{18}$ The evidence of a perfusion deficit is observed in patients with poor-grade aSAH and is believed to be a gradual effect that may correlate with disease severity. Another retrospective study of CTP demonstrated this gradual effect, comparing changes in these perfusion parameters in patients with both good-grade and poor-grade aSAH. ${ }^{23}$ These studies demonstrate the crucial importance of understanding cerebral hemodynamics in the early phase of aSAH.

The cost-effectiveness of CTP in patients with aSAH is still unknown. Sanelli et al. compared several imaging modalities for evaluating cerebral hemodynamics after aSAH, including CTA and CTP, transcranial Doppler, and digital subtraction angiography. ${ }^{11}$ They suggest that CTA with CTP is the preferred imaging strategy in patients with aSAH; however, the authors focused on delayed cerebral ischemia rather than early-stage ischemia. In our experience, the potential cost increase and the actual benefits obtained in distinguishing patients with impaired perfusion complicate the possible use of CTP in the ED setting. The technical requirement for source-image processing and the requirement for additional administration of contrast media are also major factors that limit the widespread use of CTP in the ED.

Some studies demonstrate the use of CTP in the ED, especially for patients with acute embolic stroke requiring mechanical thrombectomy procedures. The CTP modality plays a crucial role in determining the size of infarction and penumbra. These estimations critically affect the possible treatment options in this clinical scenario. However, for patients with poor-grade aSAH, the perfusion information provided by CTP is not as essential as the diagnosis of abnormal vasculature on images obtained by CTA preoperatively for directing further clipping or coiling procedures. The prognostic value of CTP may provoke its use in the future.

Similar efforts to ours were made using the cortex density in traditional CTA source images as a method of selecting patients with poor-grade aSAH.$^{14}$ Sorimachi et al. proposed the use of the density of the internal carotid artery, just proximal to the petrous portion, and the ratio of subarachnoid space to intracranial volume as possible imaging outcome markers. However, interobserver biases may complicate the use of these parameters. Instead of focusing on the arterial signal, we believe that the process of cerebral perfusion compromise begins with the delayed venous phase that is sometimes observed on traditional digital subtraction angiography.

The ultimate phase of cerebral perfusion compromise is complete arrest of cerebral blood flow, which can be demonstrated by an absence on intracranial contrast pooling in some brain-dead patients. We propose that there is a stage of partial compromise between normal perfusion and total arrest. The venous delay phenomenon on CTA helps us to identify these patients with an increased risk of ischemia. Although this imaging predictor is relatively insensitive (19.6\% in our cohort), it is the strongest surrogate for a poor outcome, with very specific prediction. Considering the common use of CTA as a primary imaging surveillance tool, almost all patients with suspected aSAH have these images performed as a survey of potential bleeding vessels. Neither extra cost nor extra contrast media are needed to complete the evaluation of the venous delay phenomenon on standard CTA, which is readily available in our routine daily practice.

However, there are some pitfalls requiring further investigation in this study. First, although the neuroradiologists responsible for image assessment were blinded to clinical outcome assessment, interobserver biases do exist during their review process, especially in cases with partial venous delay. Second, the outcome assessments were performed by the corresponding neurosurgeon alone after the primary treatment course. A certain level of discrepancies between neurosurgeons may result in lower reliability in these retrospective studies.

Hydrocephalus is another common factor that may potentially influence ICP, and also cerebral perfusion. ${ }^{10}$ In our series, all patients with poor levels of consciousness were considered to have some degree of CSF flow disturbances, and external ventricular drainage procedures were performed routinely. Hence there was no control group concerning this important clinical parameter. After the acute phase, the need for a permanent shunt procedure was determined by the neurosurgeon independently. Some biases may exist during these clinical judgments. Further prospective studies concerning these possible outcome factors in association with the venous delay phenomenon are needed to answer these questions.

Compared with the previously reported poor-outcome factors, we find that the venous delay phenomenon has the most specific prediction. We propose that this imaging 
marker can be applied easily in daily practice, and submit that our results represent convincing evidence for use of the marker as a tool for high-risk patient stratification.

\section{Conclusions}

The diverse treatment results observed in patients with initially severe SAH complicates clinical decision making. The pretreatment venous delay phenomenon on CTA with MIP represents cerebral hypoperfusion and is a strong predictor of poor outcome, in our experience. The treatment strategy should be thoroughly evaluated and the prognosis carefully explained in these patients.

\section{References}

1. Al-Mufti F, Roh D, Lahiri S, Meyers E, Witsch J, Frey HP, et al: Ultra-early angiographic vasospasm associated with delayed cerebral ischemia and infarction following aneurysmal subarachnoid hemorrhage. J Neurosurg 126:1545-1551, 2016

2. Dehdashti AR, Rufenacht DA, Delavelle J, Reverdin A, de Tribolet N: Therapeutic decision and management of aneurysmal subarachnoid haemorrhage based on computed tomographic angiography. Br J Neurosurg 17:46-53, 2003

3. Fisher CM, Kistler JP, Davis JM: Relation of cerebral vasospasm to subarachnoid hemorrhage visualized by computerized tomographic scanning. Neurosurgery 6:1-9, 1980

4. Fung C, Inglin F, Murek M, Balmer M, Abu-Isa J, Z'Graggen WJ, et al: Reconsidering the logic of World Federation of Neurosurgical Societies grading in patients with severe subarachnoid hemorrhage. J Neurosurg 124:299-304, 2016

5. Heuer GG, Smith MJ, Elliott JP, Winn HR, LeRoux PD: Relationship between intracranial pressure and other clinical variables in patients with aneurysmal subarachnoid hemorrhage. J Neurosurg 101:408-416, 2004

6. Honda M, Sase S, Yokota K, Ichibayashi R, Yoshihara K, Sakata Y, et al: Early cerebral circulatory disturbance in patients suffering subarachnoid hemorrhage prior to the delayed cerebral vasospasm stage: xenon computed tomography and perfusion computed tomography study. Neurol Med Chir (Tokyo) 52:488-494, 2012

7. Hsiang JNK, Liang EY, Lam JMK, Zhu XL, Poon WS: The role of computed tomographic angiography in the diagnosis of intracranial aneurysms and emergent aneurysm clipping. Neurosurgery 38:481-487, 1996

8. Lukosevicius S, Basevicius A, Tamasauskas A: Cerebral computed tomographic angiography scan delay in subarachnoid hemorrhage. Neurol India 53:73-78, 2005

9. Molyneux AJ, Kerr RS, Birks J, Ramzi N, Yarnold J, Sneade M, et al: Risk of recurrent subarachnoid haemorrhage, death, or dependence and standardised mortality ratios after clipping or coiling of an intracranial aneurysm in the International Subarachnoid Aneurysm Trial (ISAT): long-term follow-up. Lancet Neurol 8:427-433, 2009

10. Rosen DS, Macdonald RL: Subarachnoid hemorrhage grading scales: a systematic review. Neurocrit Care 2:110-118, 2005

11. Sanelli PC, Pandya A, Segal AZ, Gupta A, Hurtado-Rua S, Ivanidze J, et al: Cost-effectiveness of CT angiography and perfusion imaging for delayed cerebral ischemia and vasospasm in aneurysmal subarachnoid hemorrhage. AJNR Am J Neuroradiol 35:1714-1720, 2014

12. Schuss P, Hadjiathanasiou A, Borger V, Wispel C, Vatter H, Güresir E: Poor-grade aneurysmal subarachnoid hemorrhage: factors influencing functional outcome-a single-center series. World Neurosurg 85:125-129, 2016

13. Shirao S, Yoneda H, Kunitsugu I, Ishihara H, Koizumi H, Suehiro E, et al: Preoperative prediction of outcome in 283 poor-grade patients with subarachnoid hemorrhage: a project of the Chugoku-Shikoku Division of the Japan Neurosurgical Society. Cerebrovasc Dis 30:105-113, 2010

14. Sorimachi T, Osada T, Aoki R, Nishiyama J, Hirayama A, Srivatanakul K, et al: Density of the cerebral cortex in computed tomography angiography source images and clinical outcomes in Grade V subarachnoid hemorrhage. Neurol Res 37:484-490, 2015

15. St Julien J, Bandeen-Roche K, Tamargo RJ: Validation of an aneurysmal subarachnoid hemorrhage grading scale in 1532 consecutive patients. Neurosurgery 63:204-211, 2008

16. Taylor CJ, Robertson F, Brealey D, O'shea F, Stephen T, Brew $\mathrm{S}$, et al: Outcome in poor grade subarachnoid hemorrhage patients treated with acute endovascular coiling of aneurysms and aggressive intensive care. Neurocrit Care 14:341-347, 2011

17. Teasdale GM, Drake CG, Hunt W, Kassell N, Sano K, Pertuiset $\mathrm{B}$, et al: A universal subarachnoid hemorrhage scale: report of a committee of the World Federation of Neurosurgical Societies. J Neurol Neurosurg Psychiatry 51:1457, 1988

18. Tsuang FY, Chen JY, Lee CW, Li CH, Lee JE, Lai DM, et al: Risk profile of patients with poor-grade aneurysmal subarachnoid hemorrhage using early perfusion computed tomography. World Neurosurg 78:455-461, 2012

19. van den Berg R, Foumani M, Schröder RD, Peerdeman SM, Horn J, Bipat S, et al: Predictors of outcome in World Federation of Neurologic Surgeons Grade V aneurysmal subarachnoid hemorrhage patients. Crit Care Med 39:2722-2727, 2011

20. van Donkelaar CE, Bakker NA, Veeger NJ, Uyttenboogaart M, Metzemaekers JD, Eshghi O, et al: Prediction of outcome after subarachnoid hemorrhage: timing of clinical assessment. J Neurosurg 126:52-59, 2017

21. van Heuven AW, Dorhout Mees SM, Algra A, Rinkel GJ: Validation of a prognostic subarachnoid hemorrhage grading scale derived directly from the Glasgow Coma Scale. Stroke 39:1347-1348, 2008

22. Wang YC, Liu YC, Hsieh TC, Lee ST, Li ML: Aneurysmal subarachnoid hemorrhage diagnosis with computed tomographic angiography and OsiriX. Acta Neurochir (Wien) 152:263-269, 2010

23. Zhang H, Zhang B, Li S, Liang C, Xu K, Li S: Whole brain $\mathrm{CT}$ perfusion combined with CT angiography in patients with subarachnoid hemorrhage and cerebral vasospasm. Clin Neurol Neurosurg 115:2496-2501, 2013

\section{Disclosures}

The authors report no conflict of interest concerning the materials or methods used in this study or the findings specified in this paper.

\section{Author Contributions}

Conception and design: Hsieh, YM Wu, Chang. Acquisition of data: Hsieh, YM Wu, Wang, Chen, Chin. Analysis and interpretation of data: Hsieh, YM Wu, Chen, Chin. Drafting the article: Hsieh, YM Wu. Critically revising the article: Hsieh, YM Wu, CT Wu, Lee. Reviewed submitted version of manuscript: Hsieh, YM $\mathrm{Wu}$. Approved the final version of the manuscript on behalf of all authors: Hsieh. Statistical analysis: TW Wu. Administrative/technical/material support: Hsieh, YM Wu, Wang, Chen, Chang, TW Wu, CT Wu, Lee. Study supervision: Hsieh, Wang, CT Wu, Lee.

\section{Correspondence}

Po-Chuan Hsieh, Department of Neurosurgery, Chang Gung Memorial Hospital, No. 5 Fu-Shin St., Kwei-Shan, Taoyuan 333, Taiwan, R.O.C. email: pochuan.hsieh@gmail.com. 